\title{
Social Network Analysis as an Analytical Archetype of R\&D National Networks: Case Study in Culture Collections of Brazil and Japan
}

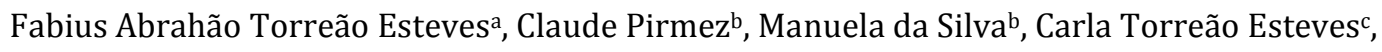
Andréa Torreão Estevesc ${ }^{c}$ Roberto Pierre Chagnona, Elton Fernandes ${ }^{\mathrm{d}^{*}}$

a Oswaldo Cruz Foundation - Fiocruz, Brazil.

b Instituto Oswaldo Cruz - IOC/Fiocruz, Brazil.

c Escola Nacional de Saúde Pública - ENSP/Fiocruz, Brazil.

d Federal University of Rio de Janeiro - COPPE/UFRJ, Brazil.

${ }^{*}$ Corresponding author's email address: elton@pep.ufrj.br

\section{A R T I C L E I N F O}

Received: 18-04-2016

Accepted: 16-05-2016

Available online: 26-05-2016

Keywords:

Analytical archetype; Brazil;

Culture Collections;

R\&D National Network;

Social network analysis.

JEL Classification: I19

\begin{abstract}
A B S T R A C T
The lack of analytical mechanisms of R\&D national networks is a significant problem for policy makers. This paper presents an analytical archetype for performance evaluation of national co-authoring networks based on Social Network Analysis parameters. The model evaluates paper co-authoring data of professionals responsible for culture collections in Brazil and Japan. Were identified professionals from the World Federation for Culture Collections data bank and co-authoring identified from international bibliographic databases. The Brazilian network is the focus of the analysis and the Japanese is the reference network. The Research and Development networks in culture collections are fundamental to the performance of the biotechnological innovation chain in areas such as health, agriculture and industry, and thus fundamental to emerging countries such as Brazil. This country has the fifth largest population in the world, being most of this population user of public health services and it has in the agribusiness one of its main sources of wealth. The model allows a performance evaluation of the networks and identifies improvement paths for the Brazilian network. SNA parameters combined with a reference network showed meaningful elements to the understanding of a R\&D networks. This proved helpful for the strategic analysis of the network weaknesses and strengths. The model also proposes policy implications for the three analysis of sub-levels, namely cohesion, subgroups and centralization.
\end{abstract}

(C) 2016 The Authors. This is an open access article under the terms of the Creative Commons Attribution License 4.0, which allows use, distribution and reproduction in any medium, provided the original work is properly cited.

DOI: http://dx.doi.org/10.18533/rss.v1i5.35.

\subsection{Introduction}

Management researchers as Peter Drucker and W. Edwards Deming are often quoted as relating management, measurement and improvement. Although this idea is quite consolidated, the mechanisms to materialize these relations, mainly in R\&D area, still face huge challenges. The Social Network Analysis (SNA) of Scientific and Technological (S\&T) institutions has shown to be a powerful tool to evaluate the performance of the Research, Development and Innovation actors (Balconi et al., 2004). Using the SNA principles and tools, this study analyses the Brazilian paper co-authoring network in culture collections, having the Japanese network as a parameter. In the field of biotechnology, universities and S\&T Institutes are Research and Development (R\&D) centres that support innovation. Through alliances and collaboration, these centres play an important role in socio-economic 
development of the countries. The scientific collaboration networks within and between organizations have been, in Brazil and in the rest of the world, the leading model to organize Research, Development and Innovation (RD\&I).

The World Federation for Culture Collections (WFCC) database , called World Data Centre for Microorganisms (WDCM), includes culture collections and not networks of collections (WFCC/WDCM, 2014). Thus, the networks of co-authoring, derived from collections, are to be interpreted as "serendipitous networks", i.e. without network governance. Alvarez et al. (2002) identify the network governance elements as: configuration or network infrastructure (e.g. actors, goals, resources, and connections); network proposal (e.g. strategy, services architecture, resources priorities, premises for decision and relevant knowledge); and network operation model (e.g. organization of network processes, nodes and resources coordination model, governance counselling, IT solutions, compliance and monitoring of the network). In the microbial area, both the Brazilian collections scientists as well as the Japanese have external co-authoring networks which are more intense than the internal ones. The global insertion is a constant and an essential search for scientists in the biotechnology area. However, when the internal R\&D networks are not robust, the benefits of knowledge creation weaken and may never happen. This is an important point of networks analysis, mainly for the formulation of public policies for S\&T financing.

The Brazilian and Japanese paper co-authoring network in cultures collections area has not been, up to here, object of study from the light of their performance and their contribution to the knowledge improvement in industry. Considering the results for R\&D, knowledge generation networks need to be evaluated and restructured periodically, under penalty of losing their effectiveness. To evaluate the performance of these networks structure measures and logical analysis are necessary. From an academic point of view, the assessments of R\&D networks do not address the performance of the network itself, but rather the evaluation of their actors. In general, they also do not present logic of comparative analysis, as a reference network. This is important because some measures do not have meaning by itself; they need a reference to be analysed.

The methodology examines the overall network configuration, including its general characteristics, the relative amount of internal and external links, institutional links and the qualitative nature of these links. In addition, parametric analysis is made from the categories and strategic considerations of strengths and weakenesses. The central issue in the article is how to structure the diagnostic performance of an R\&D network, in the case of the coauthoring network of microbiological collections of Brazil, from the SNA parameters, and comparison with a reference network of same object. This finding allows us to infer possible configuration changes and definition of structural network policies, in order to qualify their productivity both in R\&D as well as the provision of technological services.

In this paper, networks are considered "serendipitous networks" and although the SNA does not address all aspects of the network governance provided by Alvarez et al. (2002), this approach provides a significant set of governance related indicators. Thus, a set of weaknesses and strengths can be identified in order to support guideline proposals for the Brazilian network, aiming to become a R\&D network with a high biotechnological potential. The findings allow the inference of possible configuration changes and definition of improvement paths for network policies, in order to qualify networks productivity, in both R\&D as well as the provision of technological services.

The setting of these networks is analysed at the macro level and in three sub-levels: cohesion, subgroups and centralization. This paper case study is an empirical exploration of the model advocated by Van der Valk et al. (2010), but applied in distinct knowledge areas and in which there is no analysis of network performance from the SNA. The model developed allows a performance evaluation of the networks and proposes structural policies, identifying improvement paths for the Brazilian network. This policies refers to the three sub-levels.

The proposed analytical archetype introduces new measures, generating a comprehensive evaluation of the R\&D networks. A new feature of the model is the definition of parameters by categories of analysis in its maximum and minimum limits and internal and external interrelations of categories. Thus, the main question is how the comparative analysis seeks the parameters balance point for the assessment of the networks performance.

This paper is structured in six sections following this introduction: section two presents a review of the literature concerning the parameters most commonly used for networks evaluation; section 3 describes the methodology to establish the networks and the construction of the analysis framework; section 4 presents the case study consisting of two networks in analysis; section 5 discusses the results and finally, section 6 presents the conclusion pointing out the actions that may drive the generation of structural network policies. 


\section{$2.0 \quad$ Literature review}

The collaborative scientific knowledge generation, involving scientists from different countries, is observed since the $19^{\text {th }}$ century (Beaver and Rosen, 1979). Scientific collaboration networks contribute to enlarge and qualify scientific production. Authors such as Callon (1991) and Håkansson and Lundgren (1995) have shown a strong and direct relationship between RD\&I and inter-organizational interaction networks. S\&T knowledge is created and disseminated via knowledge networks nodes such as universities, research institutes and companies (Maggioni et al., 2007; Maggioni and Uberti, 2009) and, from an innovation policy view, developed countries have been changing the strategies of promoting and funding their $R \& D$ by encouraging the creation of cross-sector RD\&I networks (Corley et al., 2006).

Authors such as Callon (1992) and Orsenigo et al. (2001) show that the networks have been used in the fields of social, organizational and economic sciences to analyse institutional relationships. Hanneman and Riddle (2005) analyze the overall performance of networks through calculations of general cohesion and other calculations of more specific efficiency. However, Van der Valk et al. (2010) warn that the performance analysis has not been explored in studies of lato sensu networks. In the health area, there are studies of research networks such as Morel et al. (2009). Morel study aims to generating insights for R\&D programs, describing how organizations and authors individually act in knowledge networks, their areas of expertise, and indicates the effects on scientist performance in joining the network, but it does not make use of network parameters to evaluate performance. Coulon (2005) defines a combination of parameters for the networks performance evaluation as:

(ii) efficiency in terms of the distance between not redundant nodes (the nodes reach other nodes with not redundant links) and their not redundant size,

(iii) effectiveness in terms of the benefits of the information being centred in nodes cluster and

(iv) diversity of history of each node.

Glanzel and Schubert (2004) argue that patterns of cooperation between individuals and organizations observed in networks of co-authoring of S\&T are useful to understand and evaluate the patterns of scientific collaboration and to generate S\&T policies oriented to the strengthening of research networks in strategic areas, generating relevant effects on the dynamics of innovation. Therefore, it is necessary to analyse research coauthoring networks according to each performance: individual, collective and the resources shared.

Several authors share the opinion that networks that are not structured, managed and governed with strategies, as a rule, do not have appreciable rates of knowledge development (R\&D) of innovation and services (Raesfeld et al., 2012). Thus, the configuration of a network, defined by its players, relationships, resources and strategies, would be responsible for disseminating the knowledge, which in turn affects the innovative dynamics of the network as well as the possible services offered by it (e.g. education, supply of inputs etc.). In this context, the configuration analysis should focus on the network structure from the identification and connection between players, networks and should consider the information of social players.

There is a long tradition of investigating the social networks of academic scientists based on the SNA, using coauthoring indicators of scientific papers (Balconi et al., 2004). Several studies show that the SNA methodology is suitable for the analysis of knowledge exchanges in scientific collaboration networks, in addition to generating indicators to define structural guidelines for the development of scientific collaboration networks. It can be said that the SNA has emerged in the area of operational research, with studies of graphs. This analysis based on mathematical approaches and statistics, searches to detect and interpret relation patterns between units either individuals, institutions or nations (Wasserman and Faust, 1994). The SNA has been applied in various areas of knowledge such as health, history, information science, biology, medicine, and economics and in organizational studies. An important element that has made progress in the studies of SNA in the area of RD\&I was the organization of major international co-authoring databases of public access such as Scopus, Web of Knowledge, Scielo, among others. These have been crucial to the design and analysis of scientific collaboration networks.

The literature points to studies of specific measures of the SNA. Among them stands out the networks morphological analysis for examining the players (general cohesion and centrality) and subgroups (cohesion). Parameters such as density, brokerage, asymmetry, and kurtosis, which can have a direct influence on the formation and dissemination of knowledge of the network and, therefore, on innovation of the network should be examined.

\section{General cohesion}

Arranz and Arroyabe (2007) emphasize that the players' cohesion is important in the development of R\&D in network, whether in applied R\&D or not. However, Gilsing and Duysters (2008) warn that the cohesion from a 
certain limit may reduce the individual and collective performance (subgroup) of the network players, since it creates a restrictive environment to the influence of new ideas and, therefore, the generation of new combinations of ideas, compromising the innovative dynamic. Thus, for both low levels of cohesion and high levels of cohesion the network performance may be compromised.

It should be emphasized that there are on the market today many software programs that assists in the SNA, for example, the Ucinet software that works with multiple measures of cohesion as Average Degree, H-Index, Density, Components, Component Ratio, Connectedness, Fragmentation, Closure, Average Distance (SD Distance), Diameter, Breadth, Compactness, Krackhardt GTD and Geodesic Distance among others.

\section{Subgroups cohesion}

Hanneman and Riddle (2005) show that networks can be sectioned into regions expressed by components, bicomponents and K-core and in subgroups such as clicks, n-clicks, n-clan, K-plex, factions and f-groups. Software programs such as Ucinet make this distinction. In addition, it is possible to generate another type of partition or subgroups in the network based on criteria such as institutional affiliation or type of research object (e.g. specific search strain of a culture collection).

Girvan and Newman (2002) define the concept of communities such as the division of a network into groups, which internal connections are dense and the external connections are sparser, similar in concept to factions. It is known that subgroups sparsely connected or densely connected (cliquish effect) do not generate satisfactory performance with regard to the dissemination of knowledge. In other words, in the same way as the general cohesion, subgroups cohesion is not linear with respect to the dissemination of knowledge. According to Newman (2000, 2001 e 2004) and Wagner and Leydesdorff (2005), the best network configuration is the small world topology, since it combines the clustering of subgroups (intense knowledge sharing intra-subgroups and local trust) with the short distance between themselves (diversity and intensity of knowledge exchange intersubgroups). There are other network topologies, also called complex networks models, which are mentioned in the literature and in network software programs (e.g. Pajek) such as scale free network (Albert and Barabási, 2002).

\section{Centrality}

The most frequently used concepts of players' centrality are degree centrality, closeness centrality and betweenness centrality. Freeman (1979) shows that the networks with high degrees of centrality generally solve problems more efficiently because their leaders and team members understand with clarity their roles in the network, which favours the dissemination of knowledge in R\&D and innovation in the network. Nambisan and Sawhney (2012), for models of RD\&I focused on network, consider relevant two fundamental dimensions for the creative effort to generate innovation, which are the innovation space (continuum, from the defined to the emerging) and the leadership in the network (continuum, from the centralized to the diffuse). It should be noted that the differentiated networks in RD\&I depend on many of their central players ("entrepreneur scientists"). Therefore, the strategic position of these players must be managed so that from any new relationships defined by them, the network is not changed greatly or, in the limit, does not generate network disruptions with their absences.

The literature review indicated the contour of the methodological approach that is presented below with the identification of the parameters that will be used for the performance evaluation of the paper networks.

\subsection{Methodology}

SNA as a method for networks evaluation is the most used in the literature and was considered adequate for this paper. The specific elements to be analysed will be detailed and so theirs logical analysis. It will also be catalogued the additional elements that are part of the analysis process and limitations of scope for the research.

The R\&D networks need to be analysed from the view of the range of parameters to formulate a diagnosis of network dynamic. Thus, consideration should be given to the categories of general cohesion, cohesion of the regions/groups or subgroups and centrality of the network to analyse the strengths and weaknesses of the network. It is also noted the relevance of parameters of direct analysis of performance as presented in the efficiency analysis of the Krackhardt GTD (Ucinet software). The comparative performance analyses between networks that operate with the same object will also be used for purposes of networks evaluation, composing the assessment model in question. 
Thus, the study examines the overall network configuration, essentially, the macro morphological layout thereof, including its general characteristics, the relative amount of internal and external links, institutional links and the qualitative nature of these links. In addition, parametric analysis is made from the analysis categories (General cohesion, Subgroups cohesion and centrality).

\subsection{Analysis method of the R\&D network}

This research adopts the conceptual model of Van der Valk et al. (2010), for the purposes of co-authoring networks analysis in collections of microbiological resources (Brazil and Japan). This model assumes that there are no optimal values of the measures adopted for the R\&D networks analysis. It evaluates the performance of the R\&D networks in a comparative manner and, therefore, generates a diagnosis of strengths and weaknesses of these networks. It should be noted that the parameters/measures adopted in general cohesion, subgroups cohesion and centralization categories do not exhibit linear behaviour with the performance of the network. For example, the theoretical framework signals that for higher values of overall cohesion the network can benefit by the increment of synergy between players (strength), otherwise it can be undermined by the possibility of lock in (weakness).

From the data point of view, we worked with international databases of scientists co-authoring. The method of addressing data consists in mapping, drawing, and discussing parametric network of R\&D. Three software programs, in addition to the support of the analysis of the data in Microsoft Excel spreadsheets, were used in the analyses: Bibexcel, Pajek and Ucinet.

The first step was to select the reference country (Japan), from which the Brazilian R\&D co-authoring network would be compared. Having selected the two countries and identified the scientists from the WDCM, it was started the co-authoring networks construction working with recognized database (Scopus), identifying trustable identities (ID) of authors. Given the large amount of data, the last five years was assumed adequate for the analysis, in this case 2010-2014, and scientific papers were select as publication type. To delimit a meaningful and workable network, a cut-off of 3 papers per year was established. This cut-off point was defined from two criteria: (i) characterization of a network with a high standard of publication as referring to biotechnology sector with potential to generate technological development and (ii) that the cut-off would generate comparable networks and, therefore, with low percentage of difference of the number of players. For the interval of 5 years three possibilities were tested ( 3 papers/year, 2 papers/year and 1 paper/year) and the one that best met the two criteria was 3 papers/year. Finally, using the Pajek software, it was generated the drawing of the two networks and, therefore, an analysis of each network macro-conjuncture.

The parametric analysis, operated with the aid of Ucinet software, grouped a set of parameters/measures into three categories - general cohesion, subgroups cohesion and centrality, for individual analysis and comparison of the two networks. For the comparative analysis, since there are no optimal values for the parameters, the referential of Van der Valk et al. (2010) was used. In addition, it was introduced new analysis measures, generating a more comprehensive evaluation of the R\&D networks in relation to the theoretical framework adopted. It should be noted also about the method in question, that the authors define parameters by categories of analysis in its maximum and minimum limits and internal and external interrelations of adopted categories. Thus, the central point of the comparative performance assessment of the two networks is the way it operates the analysis of trade-off of the selected parameters, i.e., how the comparative analysis seeks the parameters balance point for the assessment of the networks performance.

\subsection{Definition of network parameters by category and its meanings}

This item introduces the architecture of parameters/measures used in the evaluation of the R\&D networks. Measures are presented by category, with its definitions, interval of values and the respective meaning to the high values of variables. The meanings for the minimum values were not explained as they can be inferred, although some are mentioned in the data analysis. Chart 1 presents the overall cohesion measures.

\begin{tabular}{lllll}
\hline \multicolumn{2}{c}{ Chart 1: Overall cohesion measures used in the study } \\
\hline Category & Measurement & Definition & $\begin{array}{l}\text { Range of } \\
\text { Values }\end{array}$ & $\begin{array}{l}\text { Meaning for high values of the } \\
\text { measures }\end{array}$ \\
\hline $\begin{array}{l}\text { General } \\
\text { cohesion }\end{array}$ & $\begin{array}{l}\text { Average Degree } \\
\text { (AD) }\end{array}$ & $\begin{array}{l}\text { Number of average links of players } \\
\text { (nodes) }\end{array}$ & AD $>0$ & $\begin{array}{l}\text { This means that the network } \\
\text { should have high amount of } \\
\text { connections }\end{array}$ \\
& Density (De) & $\begin{array}{l}\text { Number of links divided by maximum } \\
\text { possible number of links }\end{array}$ & $0<$ De $<1$ & $\begin{array}{l}\text { This means that the network } \\
\text { should have high density }\end{array}$ \\
\hline
\end{tabular}




\begin{tabular}{|c|c|c|c|}
\hline $\begin{array}{l}\text { Connectedness } \\
(\mathrm{CN}) \text { and } \\
\text { Components }\end{array}$ & $\begin{array}{l}\text { One less the fragmentation (number of } \\
\text { not reachable vertices/nodes) }\end{array}$ & $0<\mathrm{CN}<1$ & $\begin{array}{l}\text { The network is not } \\
\text { fragmented, having only one } \\
\text { component }\end{array}$ \\
\hline $\begin{array}{l}\text { Average Path } \\
\text { Length (APL) }\end{array}$ & $\begin{array}{l}\text { Average geodetic distance between } \\
\text { reachable pairs }\end{array}$ & $\mathrm{APL}>0$ & $\begin{array}{l}\text { There is a significant distance } \\
\text { between the players }\end{array}$ \\
\hline Diameter (Di) & Length of the longest geodetic distance & Di $>0$ & $\begin{array}{l}\text { There is a significant distance } \\
\text { between the players }\end{array}$ \\
\hline $\begin{array}{l}\text { Compactness } \\
\text { (CM) (cohesion } \\
\text { based on distance) }\end{array}$ & $\begin{array}{l}\text { Average of all the reciprocal distances ( } 0 \\
\text { - zero when the network is entirely } \\
\text { composed of isolate players and } 1 \text { - when } \\
\text { the network is a click - all players are } \\
\text { adjacent) }\end{array}$ & $0<\mathrm{CM}<1$ & Greater cohesiveness \\
\hline $\begin{array}{l}\text { Efficiency (EF) } \\
\text { Krackhardt GTD }\end{array}$ & $\begin{array}{l}\text { The extent to which underlying networks } \\
\text { have redundant links }\end{array}$ & $0<\mathrm{EF}<1$ & $\begin{array}{l}\text { This means that the network } \\
\text { should have lower density }\end{array}$ \\
\hline
\end{tabular}

These measures inform different views of a network overall cohesion. These views can be described as:

(i) whether there is or not fragmentation and its dimension (connectedness and components);

(ii) the average (average degree) and relative (density) number of links, and the extent to which these links effectively connect the network nodes (average path length and diameter);

(iii) network compactness (cohesion measured by distance); and

(iv) efficiency of the networks.

Burt (1992) shows some inter-relations among cohesion measures, for example:

(i) if the average number of links is low, the density is also low and the diameter is high;

(ii) if the diameter is high, the average path length is also high and compactness tends to have a lower value, decreasing the probability of cliques;

(iii) if there is fragmentation, the distance is infinite, which reduces the connectedness; and

(iv) efficiency of the network, measured by the quantity of nodes that may directly access a great quantity of different nodes through a small number of links (non-redundant contacts), increases with the shortest average path and with the lowest number of redundant contacts.

Chart 2 presents for the sub-groups cohesion category measurements with its definitions, range of values, and meanings for high values of the measures.

\begin{tabular}{|c|c|c|c|c|}
\hline \multicolumn{5}{|c|}{ Chart 2: Cohesion measures of sub-groups } \\
\hline Category & Measurement & Definition & $\begin{array}{l}\text { Range of } \\
\text { Values }\end{array}$ & $\begin{array}{l}\text { Meaning for high values of } \\
\text { the measures }\end{array}$ \\
\hline \multirow[t]{6}{*}{$\begin{array}{l}\text { Subgroups } \\
\text { cohesion }\end{array}$} & $\begin{array}{l}\text { Bicomponents } \\
\text { (Bi) (top-down } \\
\text { analysis) }\end{array}$ & Number of vulnerable blocks & $\mathrm{Bi}>0$ & $\begin{array}{l}\text { Many weak and rupture } \\
\text { players in the network }\end{array}$ \\
\hline & $\begin{array}{l}\text { Factions (Fa) } \\
\text { (top-down } \\
\text { analysis) }\end{array}$ & Number of faction blocks & $\mathrm{Fa}>0$ & $\begin{array}{l}\text { Many factions in the } \\
\text { network }\end{array}$ \\
\hline & $\begin{array}{l}\text { K-core (K-c) } \\
\text { (bottom-up } \\
\text { analysis) }\end{array}$ & $\begin{array}{l}\text { Maximum group of players being all } \\
\text { connected to } \mathrm{K} \text { other players (connected } \\
\text { maximal induced subgraph which has } \\
\text { minimum degree greater than or equal to } \mathrm{k} \text { ) }\end{array}$ & $\mathrm{K}-\mathrm{c}>0$ & $\begin{array}{l}\text { Greater number of } \mathrm{K} \text {-core } \\
\text { groups }\end{array}$ \\
\hline & EI Index (EI) & $\begin{array}{l}\text { Assesses the internal and external relations } \\
\text { - its application is considered for the } \\
\text { population and each group, meaning, the } \\
\text { network as a whole and its sub-groups can } \\
\text { be characterized in terms of the } \\
\text { boundedness and closure of its sub- } \\
\text { population }\end{array}$ & $-1<\mathrm{EI}<1$ & $\begin{array}{l}\text { The groups will have more } \\
\text { external relations than } \\
\text { internal }\end{array}$ \\
\hline & Brokerage (Br) & Type and number of intermediates by group & $\mathrm{Br}>0$ & $\begin{array}{l}\text { The groups will carry out } \\
\text { more intermediations in } \\
\text { quantity and in diversity }\end{array}$ \\
\hline & $\begin{array}{l}\text { Weighted } \\
\text { clustering } \\
\text { coefficient (CC) }\end{array}$ & $\begin{array}{l}\text { The weighted average of players clusters, } \\
\text { with the weight being the player's degree }\end{array}$ & $\begin{array}{l}0<\mathrm{CC}< \\
100 \%\end{array}$ & $\begin{array}{l}\text { The network has different } \\
\text { clusters }\end{array}$ \\
\hline
\end{tabular}

With these measures, it is possible to assess the cohesion of sub-groups on the following aspects: 
(i) whether there are cut-points players, and how many, that generate maximum number of vulnerable blocks;

(ii) how many sub-groups are factions (internally dense and sparse in external relations);

(iii) how many sub-groups there are for K-core;

(iv) the behaviour of institutional groups from the internal and external relations standpoint;

(v) the quantitative brokerage per group; and

(vi) the result from comparing the global clustering coefficient with the network's global density, checking, if there are cohesive groups on the network when such relation assumes high values.

In the same manner as for the overall cohesion, there are a certain number of possible relations among subgroups measurements. The vulnerable blocks may have similarities with the factions' blocks, which may also be formed by clicks, n-cliques or K-cores that have characteristics of more closed to the inside and less closed or boundary. The blocks that are closed more to the inside reinforce the thesis regarding the existence of cohesive groups on the network, which is verified because the clustering coefficient is higher than the density. The network brokerage analysis, which allows the network to be seen from the brokerage blocks standpoint, must have an inverse relation to the factions blocks, which are more oriented to the formation of internal clicks and less to brokerage. Partition of network into blocks (vulnerable, factions or other type) generates a standard for the network, which allows analysing the types of blocks comparatively. Furthermore, it allows generating conclusions on the risks and potentialities of the network under different cut-offs. Chart 3 presents the centrality measurements, its values intervals and meanings to the high values regarding the centrality category.

\begin{tabular}{|c|c|c|c|c|}
\hline \multicolumn{5}{|c|}{ Chart 3: Centrality measurements used in the study } \\
\hline Category & Measurement & Definition & Range of Values & $\begin{array}{l}\text { Meaning for high values of the } \\
\text { measures }\end{array}$ \\
\hline \multirow[t]{6}{*}{ Centrality } & Degree (DC) & $\begin{array}{l}\text { Direct influence measurement } \\
\text { that a player has in relation to its } \\
\text { contacts }\end{array}$ & $0<\mathrm{DC}<100 \%$ & $\begin{array}{l}\text { High quantity of players (central) } \\
\text { on the network with significant } \\
\text { direct influence on their contacts }\end{array}$ \\
\hline & $\begin{array}{l}\text { Closeness } \\
\text { (CLC) }\end{array}$ & $\begin{array}{l}\text { Related to the time that an } \\
\text { information takes to be shared } \\
\text { with all players on the network, } \\
\text { considering the shortest paths }\end{array}$ & $0<\mathrm{CLC}<100 \%$ & $\begin{array}{l}\text { High quantity of players (central) } \\
\text { on the network that are sufficiently } \\
\text { close to other players shortening } \\
\text { the time that an information takes } \\
\text { to reach all }\end{array}$ \\
\hline & $\begin{array}{l}\text { Betweenness } \\
\text { (BC) }\end{array}$ & $\begin{array}{l}\text { Considered as communication } \\
\text { control among all the other pairs } \\
\text { of players on the network, } \\
\text { considering the shortest paths }\end{array}$ & $0<\mathrm{BC}<100 \%$ & $\begin{array}{l}\text { High quantity of players (central) } \\
\text { on the network that control the } \\
\text { communication via intermediation } \\
\text { (positioning of the player on the } \\
\text { shortest path between another two } \\
\text { players) }\end{array}$ \\
\hline & $\mathrm{H}$ index (HI) & $\begin{array}{l}\text { The highest number } \mathrm{x} \text { so that } \\
\text { there are } \mathrm{x} \text { vertices of degree at } \\
\text { least equal to } \mathrm{x}\end{array}$ & $\mathrm{HI}>0$ & $\begin{array}{l}\text { Higher concentration of players } \\
\text { with high degree }\end{array}$ \\
\hline & Skewness (SK) & $\begin{array}{l}\text { Assesses the distortion of a } \\
\text { distribution (degree of } \\
\text { asymmetry) around the average }\end{array}$ & SK $=$ Any value & $\begin{array}{l}\text { Several nodes with relatively high } \\
\text { degrees (Ass }>0) \text {; several nodes } \\
\text { with relatively low degrees (Ass }<0 \text { ) }\end{array}$ \\
\hline & Kurtosis (K) & $\begin{array}{l}\text { Characterizes distribution in peal } \\
\text { or plane if compared to normal } \\
\text { distribution }\end{array}$ & $\mathrm{K}=$ Any value & $\begin{array}{l}\text { Leptokurtic distribution - some } \\
\text { nodes with very high degrees } \\
(\mathrm{C}>0) \text {. Platykurtic distribution - } \\
\text { several nodes with non-elevated } \\
\text { degrees }(\mathrm{C}<0)\end{array}$ \\
\hline
\end{tabular}

The measurements in light allow analysing the centrality of the network result of the unbalance created by the centrality of its players, assessing:

(i) the direct influence standard on the network while exposure index to which it is flowing;

(ii) how distant players are from one another in relation to the time that information takes to reach everyone;

(iii) the player's positioning frequency in the shortest path between two others;

(iv) concentration of players degrees; and

(v) characterization of network inequality comparing the degree distribution curve (assessing skewness and kurtosis) with the normal distribution curve - positive value for asymmetry indicates several nodes with relatively high degrees and negative value indicates distribution with several nodes with relatively low degrees. Positive kurtosis indicates a relatively peak distribution (a few nodes with very high degrees). Negative kurtosis indicates a relatively plane distribution (several nodes with not very high degrees). 
In the same manner as for overall cohesion and cohesion of sub-groups, there is a certain number of possible relations among the centrality measurements. Centralization in general holds direct relation with the $\mathrm{H}$ index, skewness and kurtosis of the network as these parameters indicate the concentration level of players.

Ultimately, there are relations among the previously referred analysis blocks. For example, it may be stated that density (overall connection level of the network) and centrality (connection around focal players) are complementary measurements to define the network's performance. Abbasi and Altmann (2011) affirm that the scholars with strong co-authorship links and high centrality perform better than those with weak links and low centrality. Furthermore, the efficiency of a network or high performance of the co-authors is also expanded as these strongly relate with few co-authors of a high-cohesion group. This strengthens the importance of subgroups and the ways through which sub-groups must relate each other to expand their performance. The network's brokerage blocks result from analysis of the brokerage centrality. The cut-points players (weakness points that may generate vulnerable blocks) are important as they signal the presence of key players for network integration. In general, networks with high density (low diameter) have low centralization and players are strongly connected. Highly connected players form groups or blocks that are more closed and less of boundary.

\subsection{Case study}

The main motivation for this study was the Brazilian Government initiative to set up a Brazilian Biological Resource Centres Network (CRB-Br Network) in 2014, focused on microorganisms and cells. This proposal started with the need to consolidate a network of microbial collections, which was discussed for the first time at the Second International Collections Culture Congress held by the World Federation of Culture Collection (WFCC), carried out in São Paulo in 1973, with involvement of the Brazilian Microbiology Society (SBM). Since then, there have been several initiatives and investments to reach this network consolidation, culminating in the project "Consolidation of the Brazilian Biological Resources Centres Network" approved by the Brazilian Government Agency for Financing Studies and Projects (FINEP), in 2013. According to Da Silva et al. (2011), the CRB-Br Network is a government project that derives from the Global Network of CRBs, known by the abbreviation GBRCN and presented by OCDE (2001). The proposal of the Brazilian network of CRBs is structured on four sectors, which are associated with the following anchor institutions: Fundação Oswaldo Cruz (FIOCRUZ) for health; Empresa Brasileira de Pesquisa Agropecuária for agrobusiness; Universidade de Campinas (UNICAMP) for industry and environment. In addition to these core institutions, three other organizations take part of the network in a transversal manner, each one acting in a specific system: Instituto Nacional de Metrologia, Qualidade e Tecnologia (INMETRO), Instituto Nacional de Propriedade Intelectual (INPI) and Centro de Referência em Informação Ambiental (CRIA) were appointed respectively as quality, intellectual property and information managers for the CRB-Br network. The consolidation of a Brazilian network of CRBs was based initially on the estimates of the global market for products derived from genetic resources in the areas of drugs, pesticides, agriculture and other biotechnological applications, which were in the range of 500 to 800 billion dollars year (Vazoller and Canhos, 2005). In 2014, updated estimates of the Balkan Economic Forum (2015) pointed to values in the order of 16 trillion dollars for the pharmaceutical and foods and beverages industries.

Regarding the microbiological collections, the microorganisms' networks initiatives such as the Network of International Exchange Microbes under the Asian Consortium for the Conservation and Sustainable Use of Microbial Resources (NIEMA), in advance, focus on the conservation and sustainable use of microorganisms (Ando et al., 2014). Meaning, prior to structuring a R\&D and service network in microbiological collections, there is previous concern with setting up resources negotiation criteria that respect the Biological Diversity Convention (CDB) and the Nagoya Protocol (2011) regarding access to genetic resources and fair and equal distribution of benefits resulting from use of same. In the same manner, as per Holanda et al. (2012), the goal of the Brazilian Biological Resources Centres Network (CRB-Br) is to preserve and make sustainable use of the microbial biodiversity, via platform/network of culture collections, thus having to:

(i) carry out excellence research;

(ii) offer products and services certified for the scientific community and industrial complex (repositories and information); and

(iii) promote the $\mathrm{CDB}$, including matters relating to access and distribution of benefits established in the 2011 Nagoya Protocol.

Canhos and Manfio (2000) showed that in Brazil microbial biodiversity research projects are carried out as of isolated initiatives from scientists, meaning that there is no structured network for researching microorganisms. Such reality is present to date, reason for which in 2013 the ongoing CRB-Br network project was released. In Brazil there are currently data on the microbial biodiversity integrated to data bases such as the SpeciesLink, 
Taxonline, and SiBBr. The data bases do not organize themselves as thematic networks sensu stricto, as conceived by Alvarez et al. (2002). In addition, the national program or network of biotechnology, does not account with structuring elements integrated as specialized laboratories (systematic, microbial ecology, biotechnology), CRBs, technology information centres and high-tech companies.

There is a consensus within the Brazilian Government that the country needs to be prepared to contribute in the referred areas. Within the context of the CRB-Br Network set up remains the question regarding how robust the knowledge generation of Brazilian scientists that will grant support to the national networks of CRBs is. Accordingly, the array of scientists that comprise this study was set up. This paper analytical archetype shows the position of the Brazilian scientists' network within the context of the CRB-Br Network.

\subsection{Culture collections networks of Brazil and Japan}

The CRB-Br network has at the referred anchor institutions, inasmuch its locus of governance, collections of service, of reference, and of specialized/research (SBM, 2006). The main collections of these anchors institutions are registered with the WFCC. These collections curators and directors are the co-authoring network authors that compose the object of this study. In the same manner, the Japanese main culture collections are registered at the WFCC and the curators and directors are the players of the co-authorship network to be analysed. Referred collections are part of the biological resources centres that work with live material and house biological inputs for biotechnology development (Peixoto et al., 2006). The service collections represent relevant infrastructure in the conservation and distribution of genetic resources, they have R\&D purpose in addition to providing products and services with high quality standards, one of the main objectives of the Brazilian and Global networks.

WFCC 2014 records were used as base for definition of the collections. Thus, the researching scientists, of Brazil and Japan, were identified as of the records of the respective collections. The collection data were extracted from the WDCM, which in 2014, had records of 679 culture collections of 71 different countries (WFCC/WDCM, 2014). The services offered by the collections are, by common sense, of interest to national and international biotechnology companies. Therefore, directors and curators present in the WDCM data bases form the R\&D coauthorship networks that represent the start of the biotechnological innovation chain, in general segmented from the commercial standpoint in the areas of health, agriculture, industry and environment.

The option to compare the Brazilian network with the Japanese network was because Japan, among the developed countries, has GDP and population closer to that of Brazil and because the collections of Japan are reference in the Asian continent as well as throughout the world. The objectives of the collections of both countries are similar, according to the WFCC, as they render services in storage, distribution, identification, training, and consulting. The databases of the collections of these two countries also have similarities such as:

(i) the largest contingent of the collections is of fungi and bacteria;

(ii) protozoan collections have similar percentage representability;

(iii) the contingent of yeast collections have approximate quantitative; and

(iv) the presence of few collections of cells and algae.

Thus, due to close conjuncture contexts and to objectives and nature of the collections being similar, it is assumed that the collections network of both countries provide a reasonable base for comparison of their scientists networks.

\subsection{Result and discussion}

The culture collections co-authorship networks of Brazil and of Japan for the 2010-2014 period with a 3 paper per year cut-off are shown in Figures 1 and 2. The networks were designed based on the players (scientists) related to their culture collections and respective institutions. There are a similar number of institutions involved in the two networks in question, 13 for Brazil and 12 for Japan. The Brazilian network is slightly broader, containing 34 scientists with 53 connections, while the Japanese network has 26 scientists with 67 connections. Thus, one first important aspect of the networks configuration is how much less connected the Brazilian network is in relation to the Japanese network.

Figures 1 and 2 work with two types of information, one regards the citation frequency in the original network (without cut-off), represented by the author/institution circle diameter, and other shows the co-authorship information (with cut-off), revealed by the link width as well as by the number of links between authors/institutions. Names of institutions appear with two numbers, the first signals the author number in the institution and the second his or her total number of publications (proportional to the diameter). For example, Embrapa6-19 (Figure 1) means that this is the sixth author of Embrapa with a total of 19 papers (co- 
authorships). Another important number is the one that comes associated to the links between institutions (authors), for example between Ufsc2-17 and Ufsc1-19 (Figure 1) in which there are 11 papers (coauthorships). The combination of these two information, total of co-authorships and number of links between authors/institutions, allows inferring how much the external relations of such base are larger than the internal.

Considering the comparison of the diameter value (external and internal to the network) and the co-authorship amount of links (internal to the network), it is automatic to observe how much both, the Brazilian and the Japanese networks, have several players/institutions with more external than internal links. This means that these networks have other networks. As culture collections networks are a fresh subject, it is not know to what point these are networks planned and with strategy for services and development in technology and biotechnology innovation. Meaning, these can be "serendipitous networks" where the co-authors/institutions relate without a collective concern towards R\&D results for innovation purposes.

Chart 4 presents each network institutions of Figures 1 and 2 per country and per service area. This chart shows that there are a larger number of institutions/players per service area in the Japanese network in comparison to the Brazilian network, although there is a close number of research institutions associated to the collections, 12 and 13 respectively. It also can be observed in this chart that in Brazil some institutions, such as Fiocruz and IAL, only work with one service area, which is uncommon in Japan. While in Japan, only two institutions operate in a specific area, in Brazil there are eight institutions.

\begin{tabular}{|c|c|c|c|c|c|}
\hline \multicolumn{6}{|c|}{ Chart 4: Institutions of the study per service area and country 1 and 2} \\
\hline $\begin{array}{l}\text { Collections Service } \\
\text { Area }\end{array}$ & Brazil & & & Japan & \\
\hline Healthcare & Fiocruz, Ufce, Ufrj, Ial & & 4 & $\begin{array}{l}\text { Nias, UnivTokyo, ChibaUniv, TeikyoUniv, } \\
\text { GifuUSchMe, Riken }\end{array}$ & 6 \\
\hline Agriculture & $\begin{array}{l}\text { Embrapa, Usp, Ceplac, Ufvç, } \\
\text { Fepagro }\end{array}$ & Ufpe, & 6 & $\begin{array}{l}\text { OsakaUniv, Nias, UnivTokyo, Nbrc, Riken, } \\
\text { TokyoUAg }\end{array}$ & 6 \\
\hline Environment & Ufce, Ufpe, Unesp, Ipt, Ufsc, Ufvç & & 6 & $\begin{array}{l}\text { MarineBI, Nias, UnivTokyo, ChibaUniv, } \\
\text { Nies, Nbrc, Riken, TokyoUAgT }\end{array}$ & 8 \\
\hline Industry & Fepagro, Ufpe, Unesp, Ipt & & 4 & $\begin{array}{l}\text { OsakaUniv, MarineBI, Nias, Nies, Nbrc, } \\
\text { TokyoUAg, TokyoUAgT }\end{array}$ & 7 \\
\hline
\end{tabular}

By a combining analysis of Chart 4 and Figures 1 and 2, it can be seen that Embrapa is the institution that established the largest contingent of inter-institutions connections (Maggioni et al., 2007) engaged in a single service area, while in Japan, Riken is the one with the largest amount of connections (49), although engaging in 3 service areas.

\footnotetext{
${ }^{1}$ Brazilian institutions: Fiocruz - Fundação Oswaldo Cruz; Ufce - Universidade Federal do Ceará; Ufrj - Universidade Federal do Rio de Janeiro; Ial - Instituto Adolfo Lutz; Embrapa - Empresa Brasileira de Pesquisa Agropecuária; Usp - Unviversidade de São Paulo; Ceplac (MAPA) - Comissão Executiva do Plano da Lavoura Cacaueira; Ufvç - Universidade Federal de Viçosa; Ufpe - Universidade Federal de Pernambuco; Fepagro - Fundação Estadual de Pesquisa Agropecuária (RS); Unesp - Universidade Estadual Paulista; Ipt Instituto de Pesquisas Tecnológicas; UFSC - Universidade Federal de Santa Catarina.

2 Japanese institutions: OsakaUniv - Osaka University; Nias - National Institute of Agrobiological Sciences; UnivTokyo - University of Tokyo; ChibaUniv - Chiba University; TeikyoUniv - Teikyo University; GifuUSchMe - Gifu University School of Medicine; Riken Riken Biosource Center; Nbrc - Institution Biological Resource Center, National Institute of Technology and Evaluation; TokyoUAg Tokyo University of Agriculture; MarineBI - Marine Biotechnology Institute; Nies - National Institute for Environmental Studies; TokyoUAgT - Tokyo University of Agriculture and Technology.
} 
Figure 1: Culture collections co-authorship network of Brazil based on the WFCC

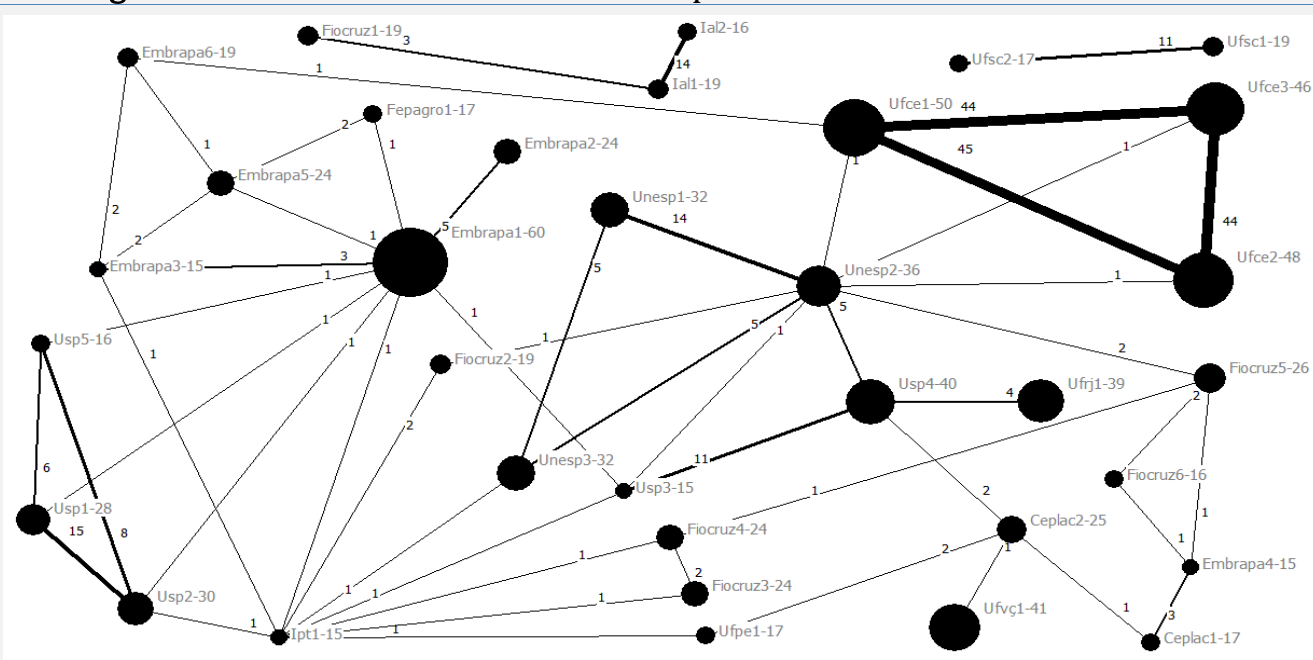

Figure 2: Culture collections co-authorship network of Japan based on the WFCC

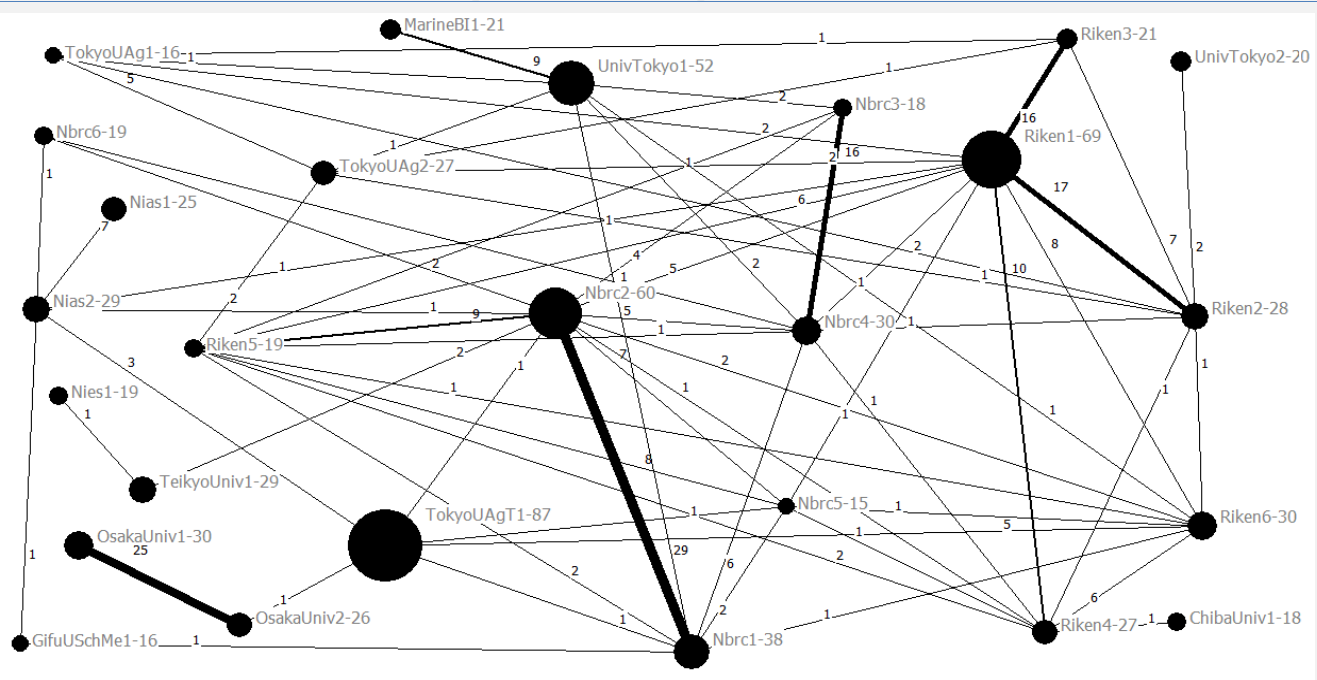

Based on the SNA, Chart 5 presents a parametric assessment of the respective co-authorship networks. This chart resumes a set of parameters/measures, which describes the co-authorship networks. These parameters/ measures compound the archetype of R\&D national networks comparative assessment.

\begin{tabular}{|c|c|c|}
\hline \multicolumn{3}{|c|}{ Chart 5: SNA results per country } \\
\hline Parameters/measures & Culture collections network of Brazil & Culture collections network of Japan \\
\hline \multicolumn{3}{|l|}{ General cohesion } \\
\hline Average Degree & 3.118 & 5.154 \\
\hline Density & 0.094 & 0.206 \\
\hline Connectedness & 0.731 & 1.000 \\
\hline Average Distance (APL) & 2.749 & 2.385 \\
\hline Diameter & 5 & 5 \\
\hline Compactness & 0.325 & 0.520 \\
\hline Efficiency (Krackhardt GTD) & 0.942 & 0.860 \\
\hline \multicolumn{3}{|l|}{ Subgroups cohesion } \\
\hline Bicomponents (cut-points and & 4 cutp / 7 blocks & 8 cutp / 9 blocos \\
\hline blocks). & 15 blocks (badness of fit $=54 ; \mathrm{fpc}=$ & 10 blocos (badness of fit $=72 ;$ fpc $=$ \\
\hline Factions (blocks) & $0.952)$ & $0.889)$ \\
\hline K-core & $\mathrm{K}=3$ & $\mathrm{~K}=5$ \\
\hline E I Index & 0.170 & 0.313 \\
\hline Brokerage & Total $=268$ & Total $=454$ \\
\hline $\begin{array}{l}\text { Clustering Coefficient (With } \\
\text { weight) }\end{array}$ & 0.287 & 0.470 \\
\hline \multicolumn{3}{|l|}{ Centrality } \\
\hline Degree & 0.189 & 0.297 \\
\hline Closeness & $40.76 \%$ & $42.47 \%$ \\
\hline Betweenness & $19.97 \%$ & $20.31 \%$ \\
\hline $\mathrm{H}$ index & 4 & 8 \\
\hline
\end{tabular}




$\begin{array}{lrr}\text { Skewness (No weight) } & (2.0315) & 1.4036 \\ \text { Kurtosis } & 4.1512 & 2.6636\end{array}$

The Brazilian network has the lowest contingent of average links, and as a consequence, the lowest density and the largest average path length. Thus, compactness of the Brazilian network is lower. The density of the Brazilian network is lower than of the Japanese network, even so, both are considered sufficiently low to generate equal diameters. Connectedness of the Brazilian network is lower than 1 (one) due to its fragmentation into three components, which does not occur with the Japanese network. The lower Brazilian compactness also favours reduction of the number of clicks of this network in relation to the Japanese network. The efficiency of the Brazilian network signals the presence of lower contingent of nodes with redundant links than the Japanese network, in accordance, also, with a lower density.

The Brazilian co-authorship network has more authors and fewer connections than the Japanese network (lower overall cohesion), signalling lower interaction among Brazilian specialists/scientists, which can be due to lower quantitative of institutional projects in this network, with Brazilians participating in co-authorships resulting from isolated initiatives of few scientists. Based on the Krackhardt GTD, the Brazilian co-authorship network has, from the structural standpoint, fewer redundant paths, although high average path length, while the Japanese co-authorship network is showing a contrary conduct.

Two analyses were carried out in relation to the cohesion of sub-groups, one defined as of the institutional subgroups (E I Index and Brokerage) and another aiming at understanding possible partitions of the network from macro to micro (top-down) and micro to macro (bottom-up) as of the vulnerabilities concepts (bi-components), factions, and clustered sub-divisions (K-core). The Brazilian network has a value of 0.17 of external internal index showing how much the 13 Brazilian institutional groups relatively aim towards internal co-authorship relations, if compared to Japanese institutional groups, which have external internal relation of 0.313 , for the 12 Japanese institutional groups. The number of internal links of the groups in Brazil (42\%) is higher than the groups in Japan (34\%), and there are more groups with high internal density in Brazil than in Japan.

The Japanese institutional sub-groups are more multi-institutional than the Brazilian sub-groups, not just because their vocation is for interaction of multi-player type as well as due to the fact that their institutions are more engaged in more than one specific area (service multi-areas of the collections), expending the possibility of engagement with players of different areas. On the other hand, the Brazilian sub-groups present more intrainstitutional than inter-institutional relations, possibly for being inserted in more specific institutions of the collections service areas and also due to the fact of possibly not being motivated, for example, by projects and bids, to expand their partnership scopes.

The clustering coefficient of the Brazilian network is inferior to that of the Japanese network, showing that the Brazilian network players have lower capacity to induce the development of clusters of their neighbours. For each one of the networks, the clustering coefficient is higher than the global density, so it can be affirmed that there are cohesive sub-groups for both networks. Furthermore, both networks present relatively low clustering coefficients.

The brokerage analysis revealed, for the five types of brokerage ${ }^{3}$, a total contingent of brokerage of the Brazilian network below to that of the Japanese network. The Brazilian network, although aimed more to the inside of groups, has inferior internal brokerage (Coordinator) than the Japanese network. The brokerage in which the broker belongs to one of the groups (Gatekeeper and Representative) is also low if compared to the Japanese. Brokerage carried out by external member to both groups (Consultant and Liaison) is also inferior on the Brazilian network. The Brazilian network has lower internal brokerage in comparison with the Japanese network, as it does not present many 3 to 3 or 4 to 4 relations, having many 2 to 2 relations. Regarding external brokerage, again, the lack of vocation for external relations between different areas of application hinders the arrival of external brokerage.

The networks bi-components analyses revealed that the Brazilian network presents just 4 cut-points, meaning that there are 4 important players that, upon absent, generate 7 non-connected blocks, while the Japanese network has 8 important player, for 9 non-connected blocks. The analysis of factions for the Brazilian network generated 15 blocks to find the best faction (elevated intra-groups connection and low inter-groups connection), while the Japanese network found the best faction with just 10 blocks. Thus, the Brazilian network needs more division than the Japanese network to find its best faction structure. As the networks of Brazil and of Japan have, respectively, 13 and 12 institutional blocks, the Brazilian network needs to divide beyond referred functional

\footnotetext{
${ }^{3}$ Coordinator - broker pertaining to the group, Gatekeeper - broker pertaining to the exit group, Representative - broker pertaining to the entry group, Consultant - external broker member in relation to the members of the same group and Liaison - external broker member in relation to the members of different groups.
} 
structure to be characterized as a faction, while the Japanese network does not need to divide beyond its 12 current blocks.

According to White and Houseman (2003), there is a relation between a small world structure and the factions, one conditioning the other. Chart 5 shows that for the "badness of fit" and "proportional correction factor" (fcp), the faction quality of the Brazilian network is better than that of the Japanese network, which accredits the Brazilian one to be closer to the definition of small world. In addition, the Japanese network has more rupture vulnerabilities than the Brazilian network due to the high number of cut-points.

The K-core showed that the Brazilian network needs K equal to 3 and the Japanese network needs $\mathrm{K}$ equal to 5. Thus, the Brazilian network sets up partitions/groups of lower interactions with other group players, meaning that the feeling of belonging to the network is smaller. Therefore, the sub-groups are more autonomous, selfreferred, in part due to the segmentation of institutions per area and in part due to the non-formal structuring in network. Ando et al. (2014) show that the NIEMA network, a culture collections network in Asia, with participation of the Japanese collections, is an initiative, which among other objectives introjects the concept of serendipitous network. This fact indicates that Japan is already inserted in a network culture, which strengthens the feeling of belonging.

The degree centrality of the Brazilian network is approximately $10 \%$ lower to that of the Japanese network, meaning how much the Brazilian players are less influent in relation to the knowledge that flows on the network. The closeness and betweenness centralities also diagnose the Brazilian network as inferior in knowledge time-sharing and in brokerage of actions. Thus, it can be affirmed that the Brazilian network is less unequal than the Japanese network as it has more centrality of degree, closeness and betweenness.

As of the degree distribution of networks it can be seen that the Brazilian $\mathrm{H}$ index is 4, signalling that Brazil has at least 4 degree vertices at least 4 , which is a very low number if compared to the Japanese value that is of 8. Furthermore, it is observed that the Brazilian skewness is lower than minus 1, which confirms that there are many players of low degree (31 players with degree 1, 2, 3, and 4), differently to the Japanese network that has positive skewness, therefore with many players of high degree. The more positive kurtosis of the Brazilian network generates a more leptokurtic format, having few players with high degree (3 with degree 9) different to the Japanese network which is less leptokurtic, having a more uniform distribution of degrees (8 players with degree above 8) and with average degree of 5.1. These measurements signalled that the Japanese network is more centralized, therefore, more unequal than the Brazilian network, which is verified by the contingent of high degree nodes combined with the quantity of nodes with very high degrees and higher average degree.

In summary, the following characteristics are present:

(i) The Brazilian network (34 players) is slightly larger that the Japanese network (26 players), and more sparse. The Japanese network is more densely connected and with higher formation of clusters, possibly due to participation in collective projects;

(ii) From the Krackhardt GTD analysis standpoint the Brazilian network, with lower contingent of redundant links nodes, is more efficient than the Japanese network. If it also had a shorter average path length, it could be affirmed that the Brazilian network would be much more efficient than the Japanese one;

(iii) The Brazilian network has lower vocation to relate externally with its institutional groups than the Japanese network, which is verified, in good part, due to the specific nature of engagement of their constituent institutions, taking as base the services collections areas;

(iv) The Brazilian network has for all type of brokerage (Coordinator, Gatekeeper Representative, Consultant and Liaison) much lower values than the Japanese network, meaning the relevant brokerage role assumed by the Japanese authors;

(v) The Brazilian network has fewer cut-points (4 players) than the Japanese network (8 players), which signals that the Brazilian network is less subject to fracture risks, additionally Japanese leaderships are in greater number and are more centralizing;

(vi) The Brazilian network has a faction structure (high internal density of blocks and sparse relation between blocks) which is better than the Japanese network due to the parameters presented, which in advance would qualify as the closest to definition of a small world network.

(vii) The Brazilian network forms partitions/groups of lower interactions with other players of the group (with at least 3 players), while the Japanese network presents of higher interactions with other players of the group (with at least 5 players). Meaning, the Brazilian network developed, comparatively, less network "feeling";

(viii) Compared to the Japanese network the Brazilian network has many players of low degree and few players of high degree. The Brazilian network is less unequal than the Japanese network as it has 
less centrality of degree, closeness and betweenness. The Brazilian network is less centralized, but also has low degree of cohesion, which may be due to the specific structure of the collections services areas of the institutions and, also, to the cultural factor.

Chart 6 presents a final comparative analysis of the two networks, showing the strengths and weaknesses concerning each network. The logic that permeates the analysis signals the trade-offs or the non-linearity of the metrics behaviour aiming at R\&D development and innovation on the networks.

\begin{tabular}{|c|c|c|}
\hline \multicolumn{3}{|c|}{ Chart 6: Weaknesses and strengths measurements/parameters per country } \\
\hline $\begin{array}{l}\text { Measurements / } \\
\text { Parameters }\end{array}$ & Weaknesses & Strengths \\
\hline \multicolumn{3}{|c|}{ Overall Cohesion (Average degree, Density, Connectedness, Average Path Length, Diameter, Compactness, Efficiency) } \\
\hline High & $\begin{array}{l}\text { Japan network: risk of local lock-in } \\
\text { (clustered/closed R\&D and Innovation) and } \\
\text { network with potential for inefficiency (more } \\
\text { nodes of redundant links) }\end{array}$ & $\begin{array}{l}\text { Japan network: generates more collective } \\
\text { benefits and has intense flow of local } \\
\text { knowledge, favouring R\&D and Innovation }\end{array}$ \\
\hline Low & $\begin{array}{l}\text { Brazil network: reduced overall and local } \\
\text { knowledge flow, may generate low potential } \\
\text { for R\&D and Innovation }\end{array}$ & $\begin{array}{l}\text { Brazil network: the network has more } \\
\text { "porosity" (open) to knowledge exchange (less } \\
\text { clustering - greater chance of Open R\&D and } \\
\text { Innovation), and with less node of redundant } \\
\text { links (with potential of efficiency) }\end{array}$ \\
\hline \multicolumn{3}{|c|}{$\begin{array}{l}\text { Cohesion Sub-groups (Bi-components (cut-points and blocks), Factions (blocks), K-core, E I Index, Brokerage, Clustering } \\
\text { Coefficient) }\end{array}$} \\
\hline High & $\begin{array}{l}\text { Japan Network: greater risk of vulnerabilities } \\
\text { ( } 8 \text { cut-points), lower contingents of intra- } \\
\text { groups relations comparatively (lower } \\
\text { cohesion intra-groups), factions of inferior } \\
\text { quality (further from the definition of small } \\
\text { world), lower institutional focus (sub-group), } \\
\text { higher risk of lock-in, decrease of network's } \\
\text { global cohesion (due to the network being } \\
\text { more unequal). }\end{array}$ & $\begin{array}{l}\text { Japan Network: many players are important for } \\
\text { non- disintegration, higher inter-groups } \\
\text { relations (higher inter-groups synergy), } \\
\text { interactions groups with more players (at least } \\
5 \text { ) - greater feeling of belonging to network, } \\
\text { higher local R\&D density, higher quantity and } \\
\text { diversity of brokerage. }\end{array}$ \\
\hline Low & $\begin{array}{l}\text { Brazil Network: few important players for } \\
\text { non- disintegration, lower inter-groups } \\
\text { relations (lower inter-groups synergy), } \\
\text { interactions groups with less players (at least } \\
\text { 3) - lower feeling of belonging to network, } \\
\text { lower local R\&D density, lower quantity and } \\
\text { diversity of brokerage }\end{array}$ & $\begin{array}{l}\text { Brazil Network: lower risk of vulnerabilities ( } \\
\text { cut-points), larger contingents of intra-groups } \\
\text { relations comparatively (higher cohesion intra- } \\
\text { groups), factions of higher quality (closer from } \\
\text { the definition of small world), higher } \\
\text { institutional focus (sub-group), lower risk of } \\
\text { lock-in, increase of network's global cohesion } \\
\text { (due to the network being less unequal) }\end{array}$ \\
\hline \multicolumn{3}{|c|}{ Centrality (Degree, Closeness (Reciprocal Distance), Betweenness, H index, Skewness (Without weight), Kurtosis } \\
\hline High & $\begin{array}{l}\text { Japan Network: strong dependence on } \\
\text { leadership - greater risk of network } \\
\text { disintegration, network more unequal with } \\
\text { centralized leadership (more visible } \\
\text { centre/periphery relation) and small decision } \\
\text { opening. The multi-thematic network allows } \\
\text { for integration of players and rise of } \\
\text { leaderships, and in increased dependence of } \\
\text { leaders }\end{array}$ & $\begin{array}{l}\text { Japan Network: greater leadership - knowledge } \\
\text { is more available and shared and } \\
\text { communication is more controlled; many } \\
\text { players with high degree of relation favouring } \\
\text { R\&D and innovation around leaderships. Many } \\
\text { players with high degrees signalling the } \\
\text { network's centrality level partly due to } \\
\text { institutions being multi-thematic }\end{array}$ \\
\hline Low & $\begin{array}{l}\text { Brazil Network: less leadership - knowledge } \\
\text { has lower sharing and communication is less } \\
\text { directed; few players with high relations not } \\
\text { favouring R\&D and innovation coordinated by } \\
\text { leaders. Few players with high degrees signal } \\
\text { the decentralization level of the network, } \\
\text { which is also verified due to being } \\
\text { monothematic. }\end{array}$ & $\begin{array}{l}\text { Brazil Network: lower risk of network } \\
\text { disintegration due to the lower dependence of } \\
\text { leaders, network less unequal, with more } \\
\text { diffuse leadership (less visible centre/ } \\
\text { periphery relation) and high decision opening. } \\
\text { Relative dependence of central actors of the } \\
\text { network in light of the network not being multi- } \\
\text { thematic and in light of the fact that the culture } \\
\text { does not favour expansion of the network. }\end{array}$ \\
\hline
\end{tabular}

\subsection{Conclusion and Policy Implications}

The aim of this study was to make a methodological contribution to the debate of R\&D national networks, having as an example the biotechnological sub-area of microbiological resources. It also aimed at highlighting the need to employ more technical management and benchmarking measures in the analysis of the networks, not just upon structuring but also in relation to the governance of $R \& D$ national networks. The paper contributes with a 
significant number of measurements/parameters and was able to show how much all the SNA parameters need to be carefully selected to find the balance point for the best performance of the networks, which became evident upon the analysis of the networks strengths and weaknesses. The analysis based solely on the morphologic structure of the R\&D network is not enough to infer about its global performance.

The main structural policies/implications reached for the three categories of measurements/parameters analyzed for the two networks were: (i) The overall cohesion of a greater density network, although with risk of lock-in, favors R\&D and innovation, closed especially in locus of greater network cluster, nut may not favor more open R\&D and innovation on the network; (ii) the more intense relations between sub-groups favor intergroups cohesion and qualify brokerage among same. Nonetheless, same may not favor intra-groups cohesion, generate factions of lower quality (more distant from a definition of small world structure) and produce several cut-points that weaken the network, compromising R\&D and innovation; and (iii) centralization also favors R\&D and innovation on the network, but up to a certain level as of which there is a strong dependence of leadership, generating a more unequal network, with presence of locus of R\&D and innovation around leaderships and not collective/distributed R\&D and innovation.

The Brazilian cultures collection network presented as main strengths the perspective of generating knowledge in a more open format, lower risk of disintegration, enhanced quality factions, lower risk of lock-in, less unequal network and less dependence of leaderships for R\&D. The greatest weakness evidenced in the Brazilian network are the reduced flow of knowledge, reduced inter-groups relation, low brokerage, lower knowledge sharing and low leadership of $R \& D$ coordination. In relation to the Japanese network, a priori with higher performance, it may be inferred that the main forces would be the intense flow of local knowledge, higher inter-groups relations and greater feeling of belonging to the network, greater brokerage, more shared knowledge and R\&D around leaderships. The greatest weaknesses presented were risk of local lock-in, potential for inefficiency, risk of vulnerability, lower institutional focus on sub-groups, higher risk of network disintegration, and more unequal network with centralized leadership.

An important matter for future researches is how external relations of R\&D national networks affect its performance. This study would identify the external relations/networks and compare it to the mapped network. This additional design would be able to reveal other standards of relations with other authors and networks. Based on the diagnosis it would be possible to design an expanded network with new references of policies, strategies, business, and management style.

In synthesis, the study presents an archetype able to produce relevant diagnostic analyses of the R\&D national network structure, strengths and weaknesses to be used by analysts of the network. Therefore, the analysed culture collection networks may be enhanced, establishing adjustments in their structure. The concept of R\&D serendipitous network must be abandon and these networks must adopt the strategized, planned, aligned and managed network concept for purposes of paving the road for innovation.

\section{References}

Abbasi A, Altmann J, (2011). On the Correlation between Research Performance and Social Network Analysis Measures Applied to Research Collaboration Networks. 44th Hawaii International Conference on System Sciences: 4-7 Jan. 2011.

Albert, R., Barabási, A., (2002). Statistical mechanics of complex networks. Reviews Of Modern Physics, 74(1), 48-97.

Alvarez RR, Da silva filho, SJM, Proença A, (2002). Redes simétricas e seu processo de definição de estratégia coletiva e modelo de governança: propostas no âmbito das redes de incubadoras e parques tecnológicos. Anais do XXII Simpósio de Gestão da Inovação Tecnológica: nov. 2002.

Ando, K., Ji T.E., Funabiki, R., Wu, L., Thoetkiattikul, H., Lee, J., Techapattaraporn, B., Changthavorn, T. (2014). Network of International Exchange of Microbes under the ACM (NIEMA) - A transfer and exchange system of microbes for microbial resource centres for non-commercial purposes according to the CBD and the Nagoya Protocol. Microbiol. Cult. Coll., 30 (2), 85-96.

Arranz, N., Arroyabe J.C.F. (2007). Governance structures in R\&D networks: an analysis in the European context. Technological Forecasting \& Social Change, 74(5), 645-662.

Balconi, M., Breschi, S., Lissoni, F. (2004). Networks of inventors and the role of academia: an exploration of Italian patent data, Research Policy, 33(1), 127-145.

Balkan Economic Forum. (2015, April 27). Retrieved from http://www.balkaneconomicforum.org/wp/marketdependence-on-genetic-resources/. 
Beaver, D.B., Rosen, R. (1979). Studies in scientific collaboration: part III: professionalization and the natural history of modern scientific co-authorship. Scientometrics, 1 (3), 231-245.

Burt, R.S. (1992). Structural holes: The Social Structure of Competition. Harvard University Press, Massachussets.

Callon, M. (1991).Techno-economic networks and irreversibility, in: Law, J., A sociology of monsters: essays on power, technology and domination. Routledge, London, pp.132-165,

Callon, M. (1992). The dynamics of techno-economic networks, in: Coombs R., Saviotti P., Walsh V., Technological change and company strategies economic and sociological perspectives. Academic Press, London, pp.72-102.

Canhos, V.P.; Manfio, G.P. (2000). (2015, April 27). Recursos Microbiológicos para Biotecnologia. Retrieved from http://www.mct.gov.br/upd_blob/0000/439.pdf.

Corley, E.A., Boardman, P.C., Bozeman, B. (2006). Design and the management of multiinstitutional research collaborations: Theoretical implications from two case studies. Research Policy, 35(7), 975-993.

Coulon, F. (2015, April 27). The use of Social Network Analysis in Innovation Research: A literature review. Retrieved from http://www.druid.dk/conferences/winter2005/papers/dw2005-305.pdf..

Da Silva, M., Cupollilo, E., Pirmez, C. (2011). Fiocruz microbial collections: the impact of biodiversity to public health. WFCC-Newsletter 51, 7-9.

Freeman, L.C. (1979). Centrality in Social Networks: Conceptual clarification. Social Networks, 1, 215-239.

Gilsing, V.A., Duysters, G.M. (2008). Understanding novelty creation in exploration networks-structural and relational embeddedness jointly considered. Technovation, 28(10), 693-708.

Girvan, M.; Newman, M.E.J. (2002). Community structure in social and biological networks. PNAS, 99 (12), 7821 7826

Glanzel, W., Schubert, A. (2004). Analyzing scientific networks through co-authorship, in: Moed, H.; Glanzel, W.; Schmoch, U., Handbook of Quantitative Science and Technology Research. Kluwer Academic Publishers, New York, pp. 257-276.

Håkansson, H., Lundgren, A. (1995). Industrial networks and technological innovation, in: Möller, K., Wilson, D., Business marketing: An interaction and network perspective. Kluwer Academic Publishers, Massachusetts, pp. 291-320.

Hanneman, R.A., Riddle, M. (2015, April 27). Introduction to Social Network Methods. Retrieved from http://faculty.ucr.edu/ hanneman/nettext/.

Holanda, P., Cavalcanti E., Borges, R.M.H., Souza, W.S. (2012). Conformity Assessment for Biological Resource Centres (BRC): The Brazilian Approach. WFCC-Newsletter 52, 8-11.

Maggioni, M.A., Nosvelli, M., Uberti, T.E. (2007). Space versus networks in the geography of innovation: a European analysis. Papers in Regional Science, 86(3), 471-493.

Maggioni, M.A., Uberti, T.E. (2009). Knowledge networks across Europe: which distance matters? The Annals of Regional Science, 43(3), 691-720.

Morel, C.M., Serruya, S.J., Penna, G.O., Guimarães R. (2009). Co-authorship network analysis: a powerful tool for strategic planning of research, development and capacity building programs on neglected diseases. PLoS Neglected Tropical Diseases, 3, e501.

Nagoya Protocol. (2015, April 27). Retrieved from www.cbd.int/abs/text/.

Nambisan, S. Sawhney, M. (2012). Network-Centric Innovation: Four Strategies for Tapping the Global Brain in: Kleindorfer, P.R., Wind, Y.J., Gunther, R.E. The Network Challenge: Strategy, Profit, and Risk in an Interlinked World. Wharton School Publishing, New Jersey, pp. 147-163.

Newman, M.E.J. (2000). Models of the small world. Journal of Statistical Physics, 101(3), 819-841.

Newman, M.E.J. (2001). The structure of scientific collaboration networks. PNAS, 98(2), 404-409.

Newman, M.E.J. (2004). Who is the best connected scientist? A study of scientific coauthorship networks. Lecture Notes in Physics, 650, 337-370.

OCDE. Biological Resource Centers: underpinning the future of life sciences and biotechnology (2015, April 27). Retrieved from http://www.oecd.org/science/biotech/2487422.pdf.

Orsenigo, L., Pammolli, F., Riccaboni, M. (2001). Technological change and network dynamics: Lessons from the pharmaceutical industry. Research Policy, 30(3), 485-508.

Peixto, A.L., Barbosa, M.R.V., Menezes, M.; Maia, L.C. (2015, April 27). Diretrizes e estratégias para amodernização de coleções biológicas brasileiras e a consolidação de sistemas integrados de informação sobre biodiversidade. Programa de Pesquisa em Biodiversidade, Ministério da Ciência e Tecnologia. Retrieved from http://www.cgee.org.br/atividades/redirect.php?idProduto $=2655$.

Raesfeld, A.V., Geurts, P., Jansen, M. (2012). When is a network a nexus for innovation? A study of public nanotechnology R\&D projects in the Netherlands. Industrial Marketing Management, 41(5), 752-758.

SBM. Proposta de Consenso: Recomendações para Operação e Gerenciamento de Coleções de Culturas de $\begin{array}{lllll}\text { Microrganismos. } & \text { (2015, } & \text { April } & \text { Retrieved }\end{array}$ https://portal.fiocruz.br/sites/portal.fiocruz.br/files/documentos/sbmgerenciamentocolecoesculturas.pdf. 
Van der Valk, T., Chappin, M.M.H., Gijsbers, G.W. (2010). Evaluating innovation networks in emerging Technologies. Technological Forecasting \& Social Change, 78(1), 25-39.

Vazoller, R.F., Canhos, V.P. (2015, April 27). Coleções de Culturas e Serviços e Centros de Recursos Biológicos. Nota Técnica. Retrieved from http://www.cria.org.br/cgee/documentos/crb.doc.

Wagner, C.S.; Leydesdorff, L. (2005). Network structure, self-organization, and the growth of international collaboration in science. Research Policy, 34(10) 1608-1618.

Wasserman, S.; Faust, K. (1994). Social Network Analysis: methods and applications. Cambridge University Press: Cambrigde.

WFCC/WDCM. (2015, April 27). Retrieved from http://www.wfcc.info/ccinfo/statistics/.

White, D.R.; Houseman, M. (2003). The Navigability of Strong Ties: Small Worlds, Tie Strength, and Network Topology: Self-organization in Strong-tie Small Worlds. Wiley Periodicals, Inc., 8 (1), 72-81. 